\title{
Simulating and Optimizing of Tramcar Transportation Attempter in Open Pit Mine
}

\author{
Chulin Chen ${ }^{*}$ and Lei Shi \\ School of Central South University, Changsha 410083, China; \\ ${ }^{*}$ Corresponding author
}

\begin{abstract}
The ore transportation system of strip mines is a representative discrete-event sys-tem, so the data concerning facilities and resource are collected and extracted to obtain their statistical probability by Expertfit; Based on Flexsim, Then 3D model is developed, incarnating the relationship among transport, resource and facilities, thereby, which vividly simulates, anal sizes and optimizes the producing-transport system of strip mines. It puts forward two dispatching method, Grade-threshold dispatching and Passive-Dispatched Truck, and sets three indexes in orthogonal designs, including truck utilization ratio, producing-facility utilization ratio and standard deviation of Aluminum to Silicon ratio(DAS). Those optimization schemes, referring to site-transportation network and dispatching plan, can minimize the cost and optimize material com-position by analyzing simulation model; It gains the optimization decisionmaking of temporary reserves in washing bauxite site, number of trucks and ways of dispatching, meanwhile, forecasts and analyzes latency influence factors and sensitivity. The simulation results validate the rationality and correctness of simulation system.
\end{abstract}

Keywords-ore transportation; flexsim; system simulation; grade-threshold dispatching

\section{INTRODUCTION}

The convey of ore is the main portion of strip mine produce, accounting for the $50 \%$ of the total transport cost, which affects seriously economic benefits of mines. Flexsim software, providing with the function of 3D display, data processing and exchanging etc, fits specially to simulate the representative discrete-event system of strip mines. The agility and reproducibility of models make for investigating sufficiently ore transportation system. It simulates the design of sitetransportation network, truck-dispatching plan in dummysimulation environment, and validates the rationality and feasibility of scheme, meanwhile, keeping producing process continuous and stable by adjusting the stability of ore degree. Moreover, the cost of ore transportation system is reduced and the utilization ratio of truck and producing equipment also are enhanced, but never affecting operation normally and enterprise safety[1][2][3].

\section{Simulation Plan}

Ping-Guo accumulative bauxite ore, Occurring more than 0.2 billion tons in Guangxi province, is infrequent and oversize, and possesses huge economic values. With low content of $\mathrm{SiO} 2$, ore is only appropriate to be smelted by pure Bayer process, which is rigorous for Aluminum to Silicon ratio (A/S) and should be kept perennially stable.

\section{A. Model Hypothesis}

It is hypothesized by actual circs in Ping-Guo bauxite accurate, as follows:(1)Don't set loading time, unloading time and number of trucks, for ore broken up can be directly conveyed.(2)Assigning in advance trucks to some stope, but dispatched in the whole diggings when required.(3)Supposing uniform motion, and set acceleration and deceleration of trucks for off-set fork-lift's loading and unloading time.(4)One washing bauxite site is interdependent with one blending rock site, $\mathrm{A} / \mathrm{S}$ are equal in each pair.

\section{B. Macroscopic Layouts}

According to actual circs, the design is done on the twolevel of macroscopic layout and microscopic dynamic dispatching to optimize transportation system as possible. Based on linear optimization, site-road plan and Ore blending plan, macroscopic layout establishes site-transportation network, mining sequence and output over time to prolong the length of service by making the most of low-degree ore and minimize total ore transportation volume and cost.

The result of multi-objective linear programming is gained by DASH, optimizing software. The pan can prolong the length of service, 6.74 and 9.85years in the 9th and 10th area, and the weighted average is 7.78, as shows in Figure 1.

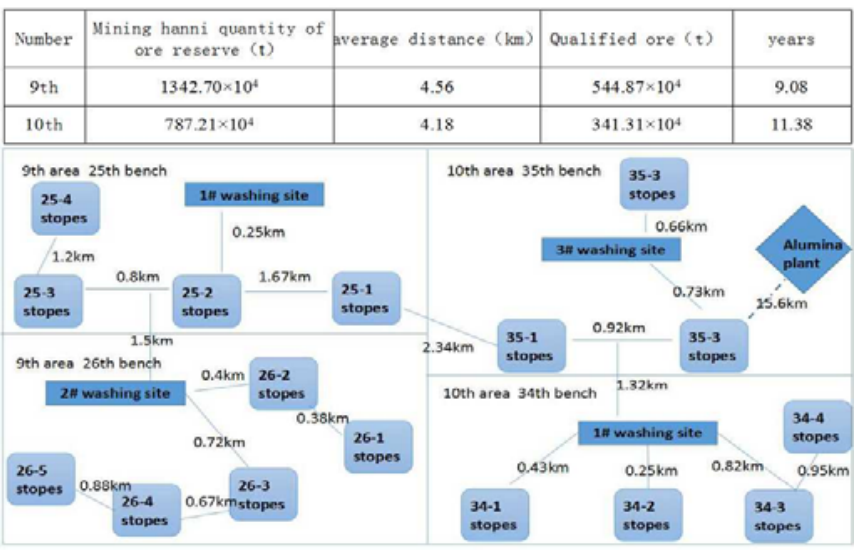

FIGURE I. SITES-TRANSPORTATION NETWORK PLAN 


\section{Microscopic Dynamic Dispatching}

Degree-Threshold Dispatching and Passive-Dispatched Truck are the main optimizing means of microscopic dynamic dispatching to enhance resource efficiency and ensure the stability of ore degree by setting three indexes: DAS, utilization ratio of truck and producing equipment[4][5].

\section{Conceptual Model}

Microscopic dynamic dispatching is constituted of trucks, washing bauxite sites and stopes, dis-patching center in PingGuo bauxite ore[6].There are two ways for dispatching: several stopes provide ore to one washing bauxite site which offers some $\mathrm{A} / \mathrm{S}$ ore in special periods to alumina refinery, and dispatching center sets the task priority of stope transportation and dispatches trucks when the $\mathrm{A} / \mathrm{S}$ exceeds some critical value in washing bauxite sites, then trucks execute task by the priority and control consequently ore degree in the blending rock site; On the other hand, idle trucks dispatched unreasonably ask dispatching center for conveying tasks, thereby, it keeps the dynamic balance of truck dispatching and enhances the utilization ratio of resource, as shows in Figure 2.

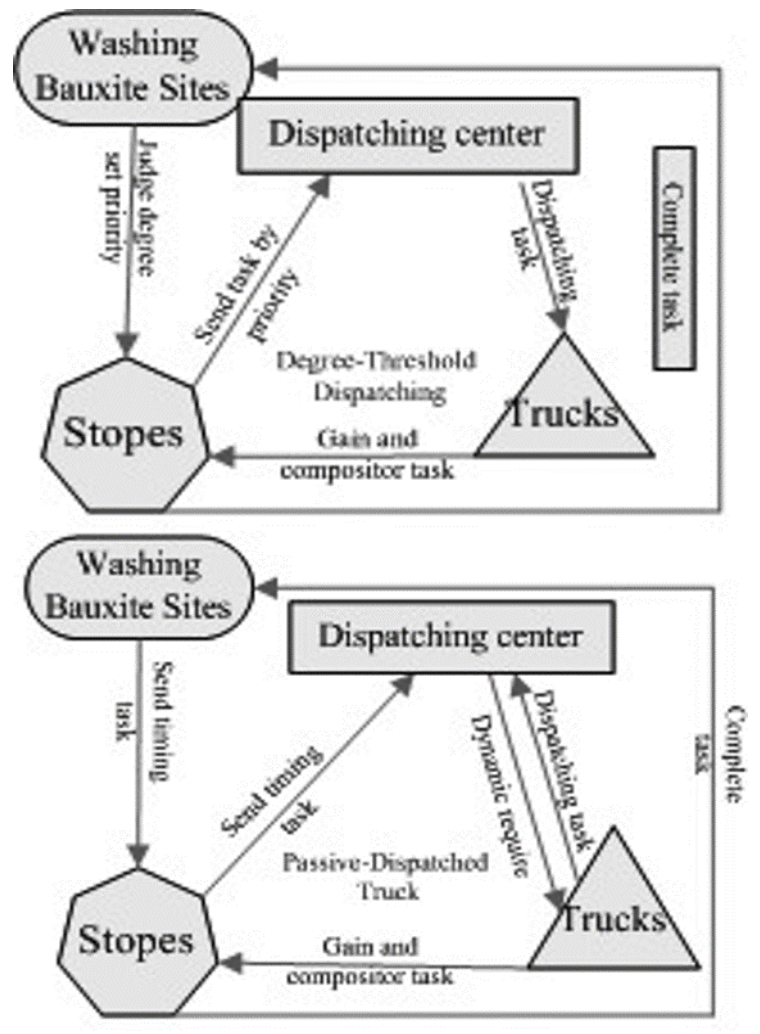

FIGURE II. DEGREE-THRESHOLD DISPATCHING THEORY AND PASSIVE DISPATCHED TRUCK THEORY

\section{E. Emluator}

It is necessary to write $\mathrm{C}++$ program on some objects in the model to actualize previous function, and the main part is offered[7][8][9], as follows in Figure 3, 4.

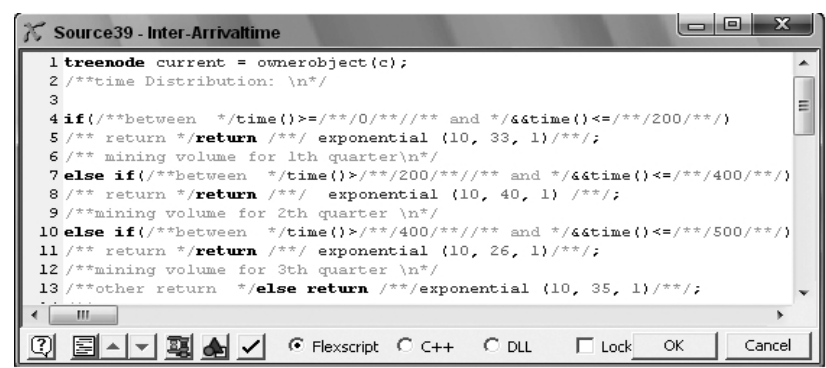

FIGURE III. MINING PROGRESS CONTROL PROGRAM

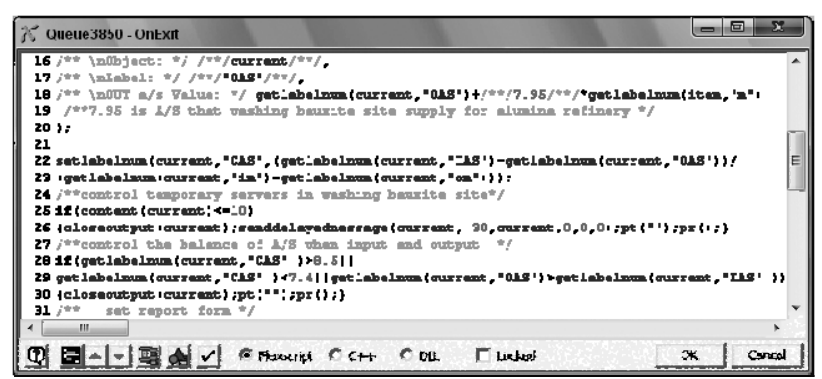

FIGURE IV. DEGREE-THRESHOLD DISPATCHING PROGRAM.

\section{SySTEM MODEL}

\section{A. Simulation Theory}

The objects in Flexsim would execute some activity and task and possess special function or inherit other function, so it can describe main characters of ore transportation and processing on ore, and change the state of objects on discretetime point by special event[10][11][12].

\section{B. Collecting and Conducting Data}

Some parameters required by simulation model are collected and dealt with by ExpertFit, to gain their probability functions, such as weight per vehicle, A/S per vehicle, vehicle failure rate, equipment failure rate, washing bauxite time per ton etc, taking now A/S per vehicle for example.

ExpertFit allows determining automatically and accurately which probability distribution best represents a data set, and presenting coincidence degree, and performs the A-D Test, the $\mathrm{K}-\mathrm{S}$ Test in order to get a formal evaluation of the best-fitting model[13].

Observed values are ranked by the degree, $\mathrm{X}(1) \leq \mathrm{X}(2) \leq \mathrm{X}(\mathrm{n})$

Thus $\mathrm{Fn}(\mathrm{x})$ and $\mathrm{F}^{*}(\mathrm{x})$ respectively rep-resents empirical dis-tribution function and hypothetic distribution function.

$$
\begin{gathered}
D_{n}^{+}=\max _{1 \leq i \leq n}\left\{\frac{i}{n}-F^{*}(X(i))\right\} \\
D_{n}^{-}=\max _{1 \leq i \leq n}\left\{F^{*}(X(i))-\frac{i-1}{n}\right\}
\end{gathered}
$$




$$
A_{n}^{2}=-n-\frac{1}{n} \sum_{i=1}^{n}(2 i-1)\left\{\ln F\left(x_{i}\right)+\ln \left[1-F\left(x_{n+1-i}\right)\right]\right\}
$$

K-S test: testing statistic Dn $=\max (\mathrm{Dn}, \mathrm{Dn}-)$, as shows in equations (1) and (2), if $\mathrm{Dn}<\mathrm{Dn}, \mathrm{a}$, hypothetic distribution function will be accept, or rejected. The ais significance level, and $\mathrm{Dn}, \alpha$ can be also obtain from K-S test table.

A-D test: testing statistic $A_{n}^{2}$, as shows in equation (3), if $A_{n}{ }^{2}<$ $A_{n}{ }^{2}, a$, hypothetic distribution function will be accept, or rejected. The ais significance level, and ${A_{n}{ }^{2}, a}_{\text {can }}$ be also obtain from A-D test table.

It can't observe which probability distribution best represents probability distribution of A/S per vehicle from the histogram, unless analyzed by virtue of Expert Fit. Three best probability functions are selected from 26 models, providing their coincidence degree (shows in Figure 5, 6).

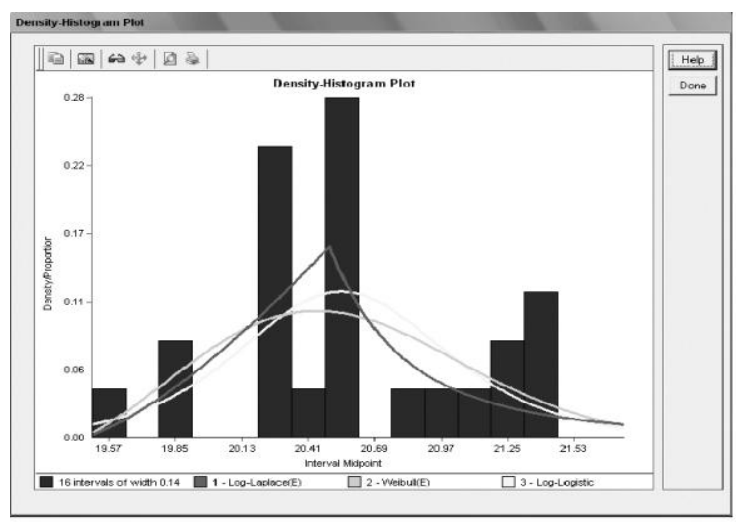

FIGURE V. BEST PROBABILITY PUNCTION OF A/S PER TRUCK.

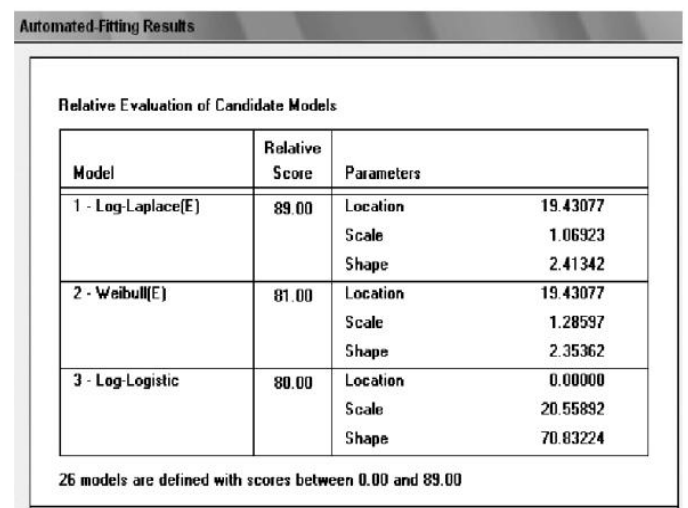

FIGURE VI. COINCIDENCE DEGREE OF PROBABILITY FUNCTIONS.

Log-Laplace best presents probability distribution of $\mathrm{A} / \mathrm{S}$ per vehicle, and isn't refused by the A-D Test (Figure 7) and the K-S Test (Figure 8), so probability distributions of other parameters are also determined similarly.

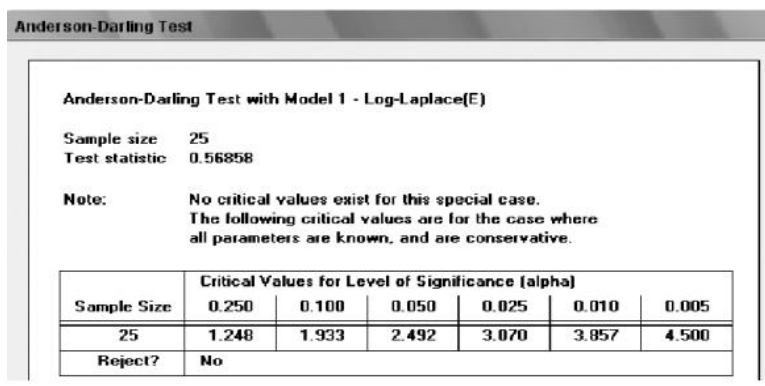

FIGURE VII. K-S TEST.

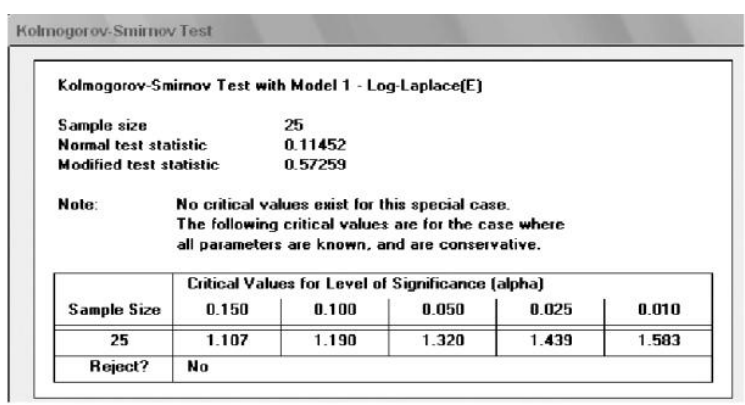

FIGURE VIII. A-D TEST.

\section{Simulation Model}

Integrated with mine environment around, then 3D simula-tion model is developed. The model mostly includes fixed objects, items and task executors. When initiating the model, items, representing ore, are birthed and endowed some attributes, such as A/S, weight, cost etc; The task executors perform the function of trucks and forklift to convey ore, which trigger discrete-event dispatching by writing $\mathrm{C}++$ program into draw menus and log information of relative data and state transformation in the attribute for exchanging with other software; Fixed objects mostly indicate stopes, washing bauxite sites and alumina refinery etc, which take charge of creating, processing and absorbing item, or executing special task by writing program. Other objects simulate vividly around circumstance, road, and charts and so on [14]. The whole model is showed in Figure 9.

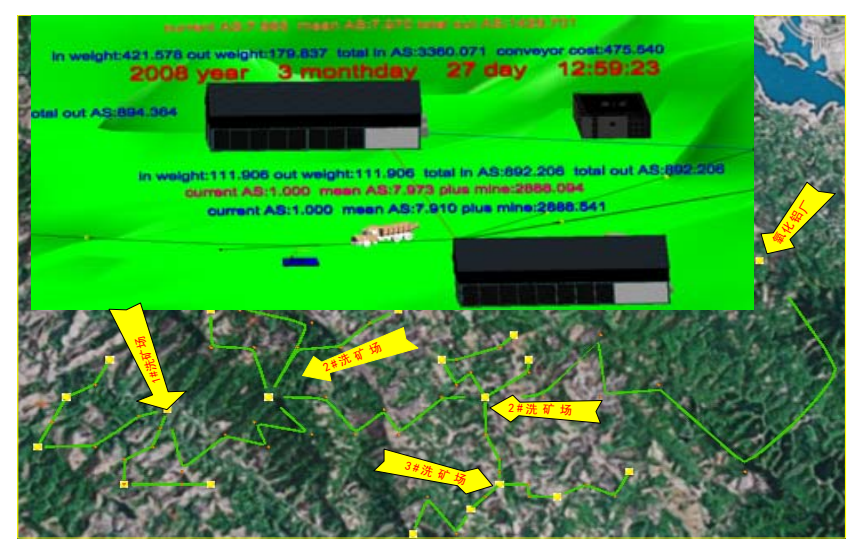

FIGURE IX. OVERALL SIMULATION MODEL OF PING-GUO BAUXITE ORE 


\section{SimUlations, ANALYZING AND VALIDATING}

\section{A. Simulation Experimentation}

The primary aim of model simulation is to reduce ore transportation cost, and ensures producing process continuously and stably, so three indexes in orthogonal designs will be set, including truck utilization ratio, producing-facility utilization ratio and $\mathrm{A} / \mathrm{S}$ standard deviation (DAS). DAS regarded as response variable, will be paid more attention to. After investigating the simulation system, there are three shadiness influence factors, quantitative factors: temporary reserves in washing bauxite sites (A), dispatched truck number (B), and qualitative factors: dispatching ways $(C)$. Those indexes must be ascertained when designing optimizing plan of ore transportation system, so orthogonal experiment is imported to find out best plan and primary influence factors in simulation experiment[15][16]

\section{[17].}

The simulation chooses $L_{9}\left(3^{4}\right)$ orthogonal table to text three levels of three factors, shown in Table1.

TABLE I. $\left(L_{9}\left(3^{4}\right)\right.$ ORthogonal TABLe $)$

\begin{tabular}{|c|c|c|c|c|c|}
\hline$a$ & $1(A)$. & $2(B):$ & $3(C)$ & $D A S$ & $\begin{array}{l}\text { Parameter } \\
\text { estimation. }\end{array}$ \\
\hline 1 & $1(5000 t)$ & $\begin{array}{c}1 \\
\text { (20trucks) }\end{array}$ & 1 (First Available) & $\mathrm{X} 11=0.393$. & $\mathrm{Al}=0.0829$. \\
\hline 2. & $1(5000 t)$ & $\begin{array}{c}2 \\
\text { (25trucks) }\end{array}$ & 2 (Shortest Distance) & $\mathrm{X} 12=0.5$. & $A_{2}=0.0086$. \\
\hline 3. & $1(5000 t)$ & $\begin{array}{c}3 \\
\text { (28trucks) }\end{array}$ & 3 (Shortest Queue) . & $\mathrm{X} 13=0.46$ & $\mathrm{~A} 3=-0.0914$. \\
\hline 4. & $2(7000 t)$ & $\begin{array}{c}1 \\
\text { (20trucks) }\end{array}$ & 2 (Shortest Distance) . & $\mathrm{X} 21=0.36$. & $\mathrm{Bl}=-0.0338$. \\
\hline 5. & $2(7000 t)$ & $\begin{array}{c}2 \\
\text { (25trucks) }\end{array}$ & 3 (Shortest Queue). & $X 22=0.42$, & $B 2=0.0586$. \\
\hline 6. & $2(7000 t)$ & $\begin{array}{c}3 \\
\text { (28trucks) }\end{array}$ & 1 (First Available) & $\mathrm{X} 23=0.35$ & B3 $=-0.0248$. \\
\hline 7. & $3(8000 t)$ & $\begin{array}{c}1 \\
\text { (20trucks) }\end{array}$ & 3 (Shortest Queue). & $\mathrm{X} 31=0.25$ & $\mathrm{Cl}=-0.0004$. \\
\hline 8. & $3(8000 t)$ & $\begin{array}{c}2 \\
\text { (25trucks) }\end{array}$ & 1 (First Available) & $\mathrm{X} 32=0.36$. & $C 2=-0.0081$. \\
\hline 9. & $3(8000 t)$ & $\begin{array}{c}3 \\
\text { (28trucks) }\end{array}$ & 2 (Shortest Distance) . & $\mathrm{X} 33=0.22$. & $\mathrm{C} 3=0.0086$ \\
\hline
\end{tabular}

Output result is tested by Variance analysis for gaining significance of factors influence, shown in Table 2:

TABLE II. VARIANCE ANALYSIS

\begin{tabular}{|l|l|c|c|}
\hline $\begin{array}{c}\text { resource of } \\
\text { Variance }\end{array}$ & sum of squares & $\begin{array}{c}\text { degree of } \\
\text { freedom }\end{array}$ & $\boldsymbol{F}$ \\
\hline Factor (A) & $\mathrm{SSA}=0.0459$ & $\mathrm{I}=2$ & $\mathrm{FA}=12.72$ \\
\hline Factor (B) & $\mathrm{SSB}=0.0156$ & $\mathrm{~J}=2$ & $\mathrm{FB}=4.31$ \\
\hline Factor (C) & $\mathrm{SSC}=0.00042$ & $\mathrm{~K}=2$ & $\mathrm{FC}=0.12$ \\
\hline $\begin{array}{l}\text { Random } \\
\text { error }\end{array}$ & $\mathrm{SSE}=0.00655$ & 2 & \\
\hline Sum & $\mathrm{SST}=0.00361$ & $\mathrm{~N}=8$ & \\
\hline
\end{tabular}

$F_{A}$ is calculated in equation (4), similarly calculating $F_{B, C}$,

$$
F_{A}=\frac{S S A /(I-1)}{S S E /(N-I-J-K)} \sim F(I-1, N-I-J-K)
$$

Choosing significance level $\alpha=0.1$, then $\mathrm{F}_{0.1}(2,2)=9.0, \mathrm{~F}_{\mathrm{A}}>9$, $F_{B}<9, F_{C}<9$,so it is obvious that temporary reserves in washing bauxite sites affects most stability of $\mathrm{A} / \mathrm{S}$ than others. The optimizing plan, $\mathrm{A} 3 \mathrm{~B} 1 \mathrm{C} 2$, is obtained, for the least values of parameter estimation are A3, B1, C2.However, the plan is missed in simulation experiment design, so DAS is 0.21 when simulating again following the plan. Then truck utilization ratio and producing-facility utilization ratio is separately 0.99 and 0.95 , and the result is great. It is feasible that orthogonal design is applied to analyze ore transportation system in strip mines.

\section{B. Output of Data and Sensitivity Analyzing}

Flexsim logs and shows relative information during running, such as cost, dynamic A/S, the change of truck utilization ratio and producing-facility utilization ratio etc. If data are exported into DDE, Excel, ODBC and Windows Sockets, it is helpful for analyzing system dynamic circs and directs Scientifically and reasonably actual producing. It takes simulation mining progress by periods in some stopes for example, compared with planning mining progress. And the results are as follow

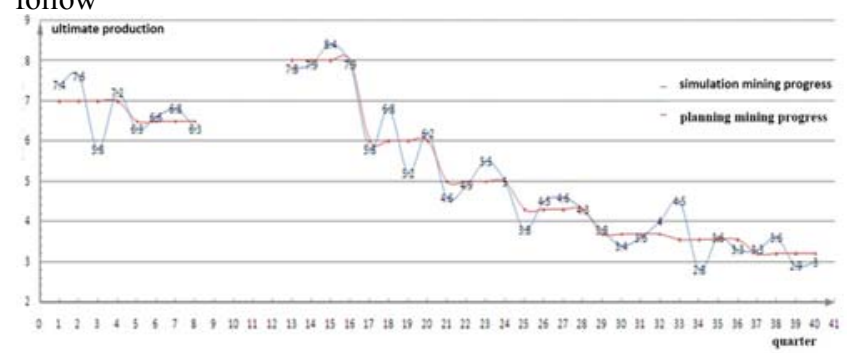

\section{FIGURE X. PLANNING MINING PROGRESS VS SIMULATION MINING PROGRESS.}

Vacancy part in the Figure 10 represents no mining plan by mining sequence in macroscopic layout.

As shows in the chart, simulation mining progress is more detailed than planning mining progress, which reflects the dynamic process of mining progress and the relation of supply, in favor of analyzing deeply system parameter and instructing actual producing plan.

According to orthogonal experiment, temporary reserves in washing bauxite sites affects most stability of $\mathrm{A} / \mathrm{S}$, so the data are exported to analyze their sensitivity for achieving the relationship graph. Adopting single factor experiment, the number of trucks is 25 and dispatching way is "First Available".

As shows in Figure 11, it is easy to know that A/S doesn't meet the standard of stably producing for little available prepared ore when temporary reserves are low. Generally speaking, the ideal value should be below 0.9. If not, alumina refinery will frequently break down, and trucks and equipments are often idle, accordingly, reducing their efficiency, eventually bottle-neck occurs in ore transportation system. 


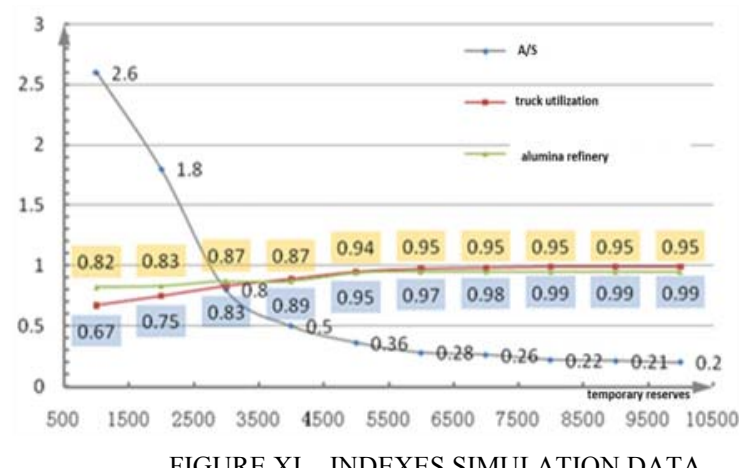

FIGURE XI. INDEXES SIMULATION DATA.

The change of DAS is little when temporary reserves is over $5.5 \times 106 \mathrm{Kg}$, meanwhile it keeps utilization ratio high and producing process stable. So the best temporary reserves in blending rock site is chose by the size of washing bauxite sites, management and maintenance measure, capital and so on.

\section{Conclusions}

The model based on Flexsim platform simulates and optimizes the whole ore transportation system of Guangxi Ping-Guo platform, including loading, transporting, dispatching, unloading and blending rock, and it achieves some fruit as follows:

1) The layout is done on the two-level of macroscopic layout and microscopic dynamic dispatching to optimize ore transportation system as possible, establishing ore transportation and site network, mining sequence and mining progress to prolong the length of service, putting forward Degree-Threshold Dispatching and Passive-Dispatched Truck, enhancing resource efficiency and ensuring the stability of ore degree;

2) Collecting and dealing with some parameters data with by ExpertFit, gaining probability functions required by simulation model, such as A/S per vehicle, vehicle failure rate etc;

3) Finding out best plan and primary influence factors in simulation experiment by analyzing temporary reserves in washing bauxite sites, dispatched truck number and dispatching ways, researching the sensitivity between temporary reserves in blending rock site and DAS, obtaining their relation graph.

The result proves that it is feasible to simulate ore transportation system in strip mines on Flexsim platform, and smooth ore transportation system simulates accurately actual process, meanwhile, simulation experiment reveals good reusability and vivid 3D display. The output data is helpful to direct actual producing and offer experience for studying dispatching ways and keeping producing process continuous and safe. It achieves those goals: investment economization, reducing producing cost, enhancing production rate and improving eventually mining synthetically efficiency.

It is rare to study the similar ore transportation system at home and abroad, so Flexsim will show without question its strong vitality, for the application on mines is just beginning. It also presents new means and concept for studying the dispatching system of stripe mines and other real-time dynamic discrete-event system[18].

\section{REFERENCES}

[1] JIAN-HONG CHEN,LI-BING YANG. 2007. Anylogic-Based Emergency Evacuation of Pe-destrians in Underground Fire [A]. Bartel Van de Walle,Xiao-di Li.INFORMATION SYSTEMS FOR CRISIS RESPONSE AND MANAGEMENT[C]. HARBIN:HARBIN ENGINEERING UNI-VERSITY PUBLISHERS, 17-23.

[2] CHEN Chong, ZHANG Ying. 2007. Simulation of Truck Dispatching System in Surface Mine Based on Extend[J]. Journal of System Simulation. 19(4):914-921.

[3] Averill M. Law, W. David Kelton. 2000. Simulation Modeling and Analysis Third edition $[\mathrm{M}]$.BeiJing: Tsinghua university publishers.

[4] XING Jun, SUN Xiao-yu. 2007. The open-pit truck dispatching method based on the com-pletion of production target and the truck flow saturation [J]. JOURNAL OF CHINA COAL SOCI-ETY. 32(5):977980.

[5] ZHAO Yong,ZHANG Ying. 2004.A DESIGN OF REAL-TIME TRUCK DISPATCHING MODEL FOR STRIP MINES BASED ON FLOW SATURATION[J]. MINING \&METALLURGY. 13(2):71-74.

[6] SUN Xiao-yu. 2006. Methods of object-oriented and center structure of truck optimized dispatch in open-pit mine [J]. Journal of Liaoning Technica University.25(1):17-20.

[7] William B. Nordgren. 2002. FLEXSIM SIMULATION ENVIRONMENT [A].Proceedings of the 2002 Winter Simulation Conference.

[8] ZHOU Yong-zheng, ZHANG San-qiang. 2006.The Model of Vehicle Dispatch for Opencut Mine Production [J]. MATHEMATICS IN PRACTICE AND THEORY. 36(7):267-274. 250-252.

[9] Zhang Bai-gen. 2002.Design of Dispatching Algorithm for Computer Automatic Dispatching Sys-tem of Trucks at Open-pit Mines [J]. METAL MINE. 315(9):35-38.

[10] Flexsim Simulation Software User Guide. Copyright . 2001-2006, Flexsim Software Products,Inc.

[11] SUN Xiao-ming. 2006. Simulation and Modeling of Producing System [M].Shanghai: Shanghai Jiao Tong University publishers.

[12] Zhang xiao-ping.2005.Theory and Application of Logistics System Simulation Beijing:China Lo-gistics Publishing House.

[13] WANG Qiang, ZHANG Ying.2006. Probability distribution of key time parameters in open-pit mine truck dispatching [J]. JOURNAL OF CHINA COAL SOCIETY. 31(6):761-764.

[14] ZHANG Jie, ZHANG Ying. 2004. Object-oriented Visual Simulation for Truck Dispatching Sys-tem in Surface Mine[J].JOURNAL OF SYSTEM SIMULATION. 16(3):538-545.

[15] Wang Guo-fu,Wang Zhi-zhong. 2003. Applied Statistical Mathematics [M].Changsha:Central South University publishers.

[16] Ma yi-fei, Li xiang-yi. 1999. Optimal Control Criteria and Their Accomplishment for Truck Dis-patch System in Opencast Mining [J].China Mine. 8(4):67-70.

[17] Ma yi-fei, Li xiang-yi. 1999. A MathematicalModel of Optimal Control for Truck Dispatching System in Opencast Mining [J]. China Mine Magazine. 8(2):63-66.

[18] JerryBanks,John S. Carson, et al. 2005.Discrete-Event System Simulation (4th edition)[M].China Machine Press 